\title{
Secondary prevention of major cerebrovascular events with seven different statins: a multi- treatment meta-analysis
}

This article was published in the following Dove Press journal:

Drug Design, Development and Therapy

30 August 2017

Number of times this article has been viewed

\section{Ping Zhong ${ }^{1,2, *}$ \\ Danhong $\mathrm{Wu}^{3, *}$ \\ Xiaofei $\mathrm{Ye}^{4}$ \\ Ying $\mathrm{Wu}^{2}$ \\ Tuming $\mathrm{Li}^{2}$ \\ Shuwen Tong ${ }^{2}$ \\ Xueyuan Liu ${ }^{1,5}$}

'Department of Neurology, Shanghai Tenth People's Hospital, Nanjing Medical University, ${ }^{2}$ Department of Neurology, Shanghai Traditional Chinese and Western Medicine Hospital, Shanghai University of Traditional Chinese Medicine, ${ }^{3}$ Department of Neurology, Shanghai Fifth People's Hospital, Fudan University, ${ }^{4}$ Department of Statistics, Second Military Medical University, ${ }^{5}$ Department of Neurology, Shanghai Tenth People's Hospital, Tongji University, Shanghai, People's Republic of China

*These authors contributed equally to this work

Correspondence: Xueyuan Liu Department of Neurology, Shanghai Tenth People's Hospital, Nanjing Medical University, No 3I Middle Yanchang Road, Jingan District, Shanghai 200072, People's Republic of China

Tel +86 2l 66302582

Email liu1304@yeah.net
Background: Statins have been recommended for the use in atherosclerotic cardiovascular diseases, but different statins have distinct pharmacological characteristics. This multi-treatment meta-analysis aimed to evaluate the efficacy of seven statins in the secondary prevention of major cerebrovascular events (CVEs).

Methods and analyses: The PubMed, Embase, Cochrane Database of Systematic Reviews and Cochrane Central Register of Controlled Trials were searched to identify studies published between January 1, 2011, and June 30, 2016. The included randomized controlled trials investigated the efficacy of lovastatin, atorvastatin, fluvastatin, simvastatin, pitavastatin, pravastatin or rosuvastatin in the secondary prevention of CVEs. The primary outcomes were CVEs; the secondary outcomes were all-cause death, fatal stroke and nonfatal stroke. Meta-analysis and network meta-analysis were used for data synthesis.

Results: A total of 42 studies with 82,601 patients were included for analysis. In the secondary prevention of cardiovascular diseases, the major CVEs in pravastatin (risk ratio [RR] 0.87, 0.76-0.99)- and atorvastatin (RR 0.59, 0.49-0.72)-treated patients reduced significantly compared with controls. Indirect comparisons with network meta-analysis showed that RR was 0.60 (0.40-0.92) for atorvastatin compared with rosuvastatin. Compared to controls, the all-cause death was reduced by $12 \%$ in statins-treated patients (RR $0.88,0.81-0.96$ ). Indirect comparisons with network analysis showed a significant difference in the nonfatal stroke between fluvastatintreated patients and lovastatin-treated patients (RR 0.28, 0.07-0.95).

Conclusion: Different statins have distinct pharmacological characteristics, and there are differences in statistical and clinical outcomes among several statins.

Keywords: atherosclerotic cardiovascular disease, cerebrovascular event, randomized, controlled trial, primary outcome

\section{Introduction}

In the past century, the disease profile changed significantly worldwide. Atherosclerotic cardiovascular disease (ASCVD) accounted for 1/10 of causes of death in early 1900s, but it has been the leading cause of death worldwide so far, accounting for one-third of causes of death. The prevalence of ASCVD increases with age. In addition, its prevalence further elevates in late life with the reduced mortality related to infection and malnutrition. Thus, ASCVD is affecting the decision making of world public health policy. Ischemic stroke is one of the most important clinical types of ASCVD and has a high recurrence rate. The ischemic stroke-related neurological impairment and subsequent emotional dysfunction and social dysfunction bring a great burden to the society and the families of these patients. Currently, controlling the serum lipid 
marker (low-density lipoprotein cholesterol [ LDL-C]) is crucial to reduce the recurrence rate of transient ischemic attack (TIA) or ischemic stroke. ${ }^{1}$

To date, statins (3-hydroxy-3-methylglutaryl-coenzyme A reductase inhibitor) have been widely used in the lipidlowering therapy. On the basis of findings from randomized controlled trials (RCTs), statins have been a major strategy in reducing the risk for ASCVD. ${ }^{2}$ Several clinical trials have shown that statins can significantly reduce serum LDL-C and effectively decrease the risk for stroke. ${ }^{3}$ Statins can reduce the incidence of major cardiovascular events, and thus, they have been recommended for the secondary prevention of ischemic stroke. ${ }^{1,4,5}$ In addition, there is evidence showing that high-dose statins are better to reduce the risk for stroke compared to standard-dose statins. ${ }^{6}$ However, there is still controversy on the clinical effects of different statins on the outcomes of ASCVD. A study indirectly compared influence of atorvastatin, pravastatin and simvastatin on the cerebrovascular events (CVEs), but it was a placebocontrol study with a small sample size and there were active comparator trials in this study. ${ }^{7}$ The network meta-analysis was conducted to evaluate the RCT that investigated the effects of primary and secondary prevention with atorvastatin, fluvastatin, lovastatin, pitavastatin, pravastatin, rosuvastatin or simvastatin in CVD patients, but it excluded head-head evaluation of different statins. Although another network meta-analysis used head-head evaluation, but pitavastatin was not investigated. ${ }^{8}$ Moreover, the incidence of cerebrovascular diseases was not a primary outcome in previous head-head network meta-analysis. ${ }^{9-12}$

Different statins have distinct pharmacological characteristics. As the number of patients in need for statin therapy continues to increase, information regarding the relative efficacy of statins is needed for better decision making. Meta-analysis with a large amount of updated data may provide true and strict clinical evaluation and accurately assess the therapeutic efficacy. This meta-analysis aimed to systemically evaluate the efficacy of statins in clinical studies that were conducted between statins-treated patients and routine controls or placebo controls and different statintreated patients. In addition, the role of different statins in the secondary prevention of major CVEs was evaluated in patients with cardiovascular diseases.

\section{Methods and analyses Systematic review methods}

We searched PubMed, Embase, Cochrane Database of Systematic Reviews and Cochrane Central Register of Controlled
Trials to identify studies published between January 1, 2011, and June 30, 2016. We identified the studies prior to January 2011 from the bibliography of previously published systematic literature reviews and meta-analyses. We used the search terms "lovastatin", "atorvastatin", "fluvastatin", "simvastatin”, "pitavastatin”, "pravastatin", "rosuvastatin", "cardiovascular disease" and "HMG-CoA reductase inhibitors/therapeutic use". Two reviewers (PZ and DW) independently performed abstract, title and full-text screening and entered data into a data extraction form. A third reviewer (YW) approved the study selection.

The inclusion criteria were as follows: 1) open and double-blind RCTs were included; 2) head-head studies or those with placebo, diet or routine therapy as a control were included; 3) patients had cardiovascular diseases; 4) the number of patients was $>60 ; 5$ ) atorvastatin, fluvastatin, lovastatin, pitavastatin, pravastatin, rosuvastatin or simvastatin was used for $>4$ weeks and 6) the primary outcomes were major CVEs, and the secondary outcomes were all-cause death, fatal stroke and nonfatal stroke. The major CVEs in this study included fatal stroke, nonfatal stroke and TIA; the nonfatal stroke did not include TIA. In addition, clinical studies in which there were patients with renal dysfunction were excluded. The study characteristics, including methods, participants, interventions and outcomes, were extracted from each study ( Supplementary material).

\section{Statistical analysis}

To summarize all available evidence, we conducted both direct and network meta-analyses. First, we did traditional pairwise meta-analysis for direct comparisons between two treatment arms by Review Manager 5.1. In the conventional direct meta-analysis, two or more studies that compared two interventions of interest were statistically combined. We calculated the pooled risk ratio (RR) with a 95\% CI. Heterogeneity was assessed using the Cochran's Q and $I^{2}$ statistics. For the $\mathrm{Q}$ statistic, a $P$-value $>0.10$ and for the $\chi^{2}$ test and for the $I^{2}$ statistic, an $I^{2}$ value $<25 \%$ were interpreted as low-level heterogeneity. A pooled effect was calculated with a fixed-effect model when there was no statistically significant heterogeneity; otherwise, a randomeffect model was used.

A network meta-analysis was conducted using a Bayesian Markov Chain Monte Carlo method and fitted in $\mathrm{R}$ package. Analytical results are presented as RR with $95 \%$ credible intervals (CrIs). The RR was estimated using the median of the posterior distribution, and 95\% CrIs were obtained based on the 2.5 th and 97.5 th percentiles of the 
posterior distribution, which can be interpreted in the same way as conventional 95\% CIs. Rankings for the treatment efficacy of the interventions were originally derived from Monte Carlo simulations and presented as the probability of possessing a specific ranking; the probabilities of different rankings of the same treatment were summed to $100 \%$. Pooled results were considered as statistically significant for $P<0.05$ or if the $95 \%$ CI (CrI) did not contain the value 1 . In this study, the patient samples from different statins were weighted in both pairwise meta-analysis and network meta-analysis.

\section{Results}

\section{General data}

A total of 20,770 studies potentially related to the topic were identified, of which 607 studies were included for final analysis and 20,163 unrelated studies that did not meet the inclusion criteria were excluded (Figure 1). In addition, 42 clinical trials published between 1994 and 2016 were included for network meta-analysis. The general information of these studies is presented in Table 1. In the studies included for network meta-analysis, 82,601 subjects received treatment with one of seven statins and $24.1 \%$ subjects were female. Of these studies, treatment with one statin was compared with control (placebo treatment, routine treatment or diet treatment) in 32 studies. Of these 32 studies, pravastatin was evaluated in 13 studies, ${ }^{13-25}$ atorvastatin in seven, ${ }^{26-32}$ lovastatin in three, ${ }^{33-35}$ simvastatin in three, ${ }^{36-38}$ fluvastatin in three, ${ }^{39-41}$ rosuvastatin in two ${ }^{42,43}$ and pitavastatin in one. ${ }^{44}$ In 10 studies, the treatment with one statin was compared with therapy of another statin. ${ }^{45-54}$ In these 10 studies, a statin was used at two doses in one study, ${ }^{54}$ the head-head study of atorvastatin and pravastatin was found in four studies, ${ }^{45,46,48,51}$ head-head study of atorvastatin and rosuvastatin was found in three studies ${ }^{49,50,54}$ (rosuvastatin at two doses was used in one study), head-head study of atorvastatin and simvastatin was found in two studies ${ }^{52,53}$ and head-head study of rosuvastatin and simvastatin was found in one study. ${ }^{47}$ The follow-up period ranged from 143 weeks to 317 weeks. In five studies, the follow-up period was $<24$ weeks. Figure 2 shows the meta-analysis of seven statins in the prevention of major CVEs.

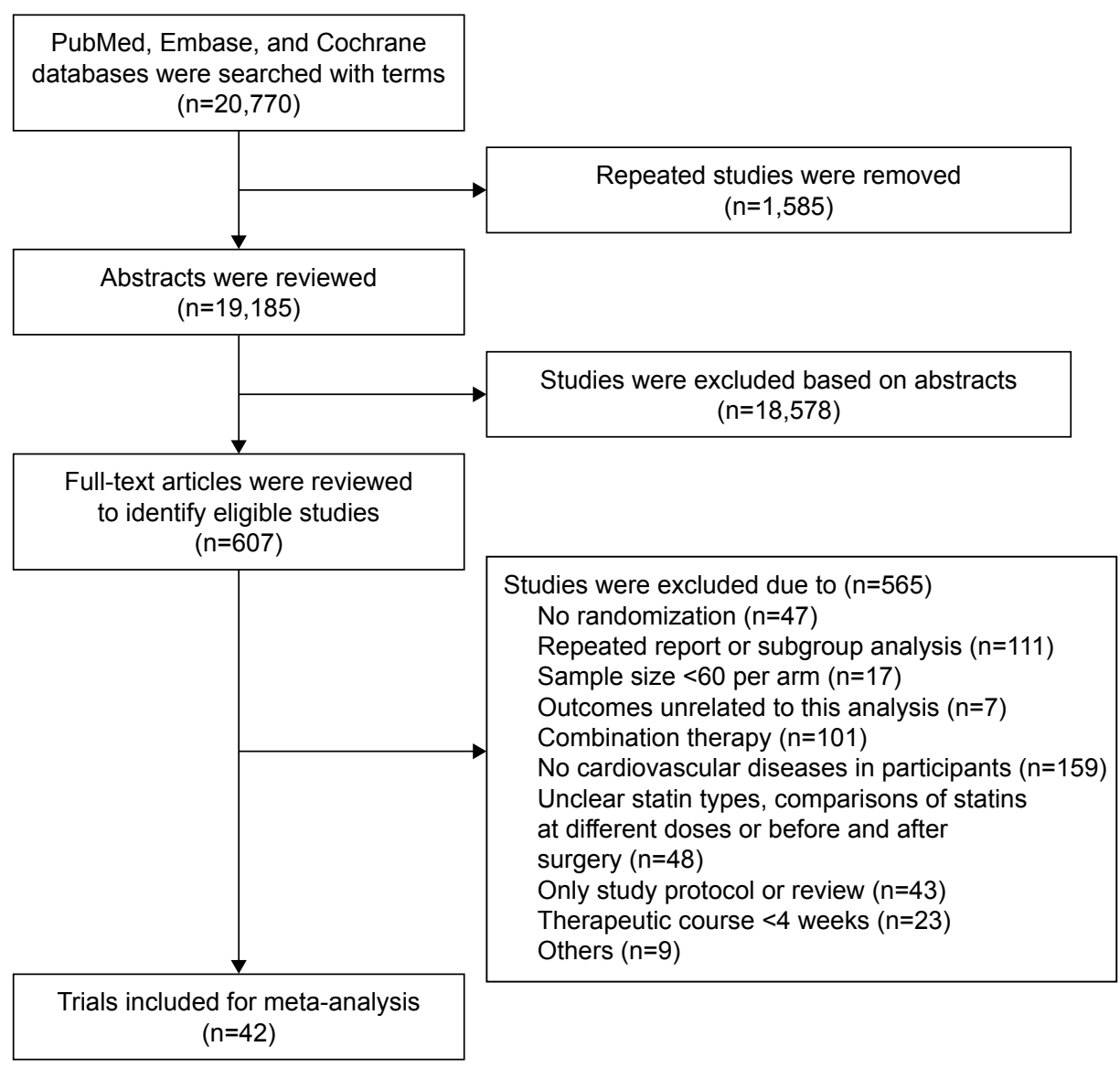

Figure I Flowchart of study inclusion. 
Table I Characteristics of studies included

\begin{tabular}{|c|c|c|c|c|c|c|c|c|c|c|}
\hline Year & Trial name & $\begin{array}{l}\text { Mean } \\
\text { age, years }\end{array}$ & $\%$ woman & Treatment & $\begin{array}{l}\text { Number } \\
\text { randomized }\end{array}$ & $\begin{array}{l}\text { Major } \\
\text { cerebrovascular } \\
\text { events, } \mathbf{n}\end{array}$ & $\begin{array}{l}\text { All-cause } \\
\text { death, } n\end{array}$ & $\begin{array}{l}\text { Fatal } \\
\text { stroke, n }\end{array}$ & $\begin{array}{l}\text { Nonfatal } \\
\text { stroke, n }\end{array}$ & TIA, $\mathbf{n}$ \\
\hline \multirow[t]{2}{*}{1993} & MARS $^{33}$ & 58 & 9 & Lovastatin & 123 & NR & 2 & NR & NR & NR \\
\hline & & 58 & 9 & Placebo & 124 & NR & 1 & NR & NR & NR \\
\hline \multirow[t]{2}{*}{1994} & $4 S^{36}$ & 58.6 & 19 & Simvastatin & 2,221 & 124 & 182 & 14 & 95 & 19 \\
\hline & & 58.6 & 18 & Placebo & 2,223 & 102 & 256 & 12 & 61 & 29 \\
\hline \multirow[t]{2}{*}{1994} & MAAS $^{37}$ & 54.9 & 12 & Simvastatin & 193 & NR & 4 & NR & NR & NR \\
\hline & & 55.6 & II & Placebo & 188 & $N R$ & 11 & NR & NR & NR \\
\hline \multirow[t]{2}{*}{1994} & $\mathrm{CCAIT}^{34}$ & 53 & 18 & Lovastatin & 165 & 0 & 2 & 0 & NR & NR \\
\hline & & 53 & 19 & Placebo & 166 & 0 & 2 & 0 & NR & NR \\
\hline \multirow[t]{2}{*}{1994} & LRTS $^{35}$ & 62 & 28 & Lovastatin & 203 & 0 & 3 & NR & 0 & $N R$ \\
\hline & & 62 & 29 & Placebo & 201 & 1 & 1 & NR & I & NR \\
\hline \multirow[t]{2}{*}{1995} & PLAC-II' & 63 & 15 & Pravastatin & 75 & $N R$ & 3 & NR & NR & NR \\
\hline & & 63 & 15 & Placebo & 76 & NR & 5 & NR & $N R$ & NR \\
\hline \multirow[t]{2}{*}{1995} & REGRESS ${ }^{17}$ & 56.5 & 0 & Pravastatin & 450 & NR & 5 & 0 & $N R$ & NR \\
\hline & & 55.9 & 0 & Placebo & 434 & $N R$ & 7 & 0 & NR & NR \\
\hline \multirow[t]{2}{*}{1995} & PLAC-120 & 57 & 62 & Pravastatin & 206 & 0 & 4 & 0 & 0 & NR \\
\hline & & 57 & 62 & Placebo & 202 & 2 & 6 & 0 & 2 & NR \\
\hline \multirow[t]{2}{*}{1996} & CARE $^{21}$ & 59 & 14 & Pravastatin & $2,08 I$ & 54 & $N R$ & $N R$ & 54 & NR \\
\hline & & 59 & 14 & Placebo & 2,078 & 78 & $N R$ & NR & 78 & $N R$ \\
\hline \multirow[t]{2}{*}{1997} & PREDICT $^{15}$ & 58.5 & 17 & Pravastatin & 347 & 1 & 4 & 1 & NR & NR \\
\hline & & 58.2 & 15.6 & Placebo & 348 & 0 & 1 & 0 & NR & NR \\
\hline \multirow[t]{2}{*}{1998} & LIPID $^{13}$ & 62 & 17 & Pravastatin & 4,512 & 169 & 498 & NR & $N R$ & NR \\
\hline & & 62 & 17 & Placebo & 4,502 & 204 & 633 & $N R$ & NR & NR \\
\hline \multirow[t]{2}{*}{2000} & GISSP-PI & 59.7 & 13.3 & Pravastatin & 2,138 & 20 & 72 & 4 & 16 & NR \\
\hline & & 60 & 14.2 & Placebo & 2,133 & 19 & 88 & 4 & 15 & NR \\
\hline \multirow[t]{2}{*}{2000} & $\mathrm{SCAT}^{38}$ & 61 & 13 & Simvastatin & 230 & 4 & 13 & NR & 4 & NR \\
\hline & & 61 & 9 & Placebo & 230 & 2 & 6 & NR & 2 & NR \\
\hline \multirow[t]{2}{*}{2001} & MIRACL ${ }^{31}$ & 65 & 35.5 & Atorvastatin & I,538 & 12 & 64 & 3 & 9 & NR \\
\hline & & 65 & 34.1 & Placebo & I,548 & 24 & 68 & 2 & 22 & NR \\
\hline \multirow[t]{2}{*}{2002} & $\mathrm{GREACE}^{27}$ & 58 & 22 & Atorvastatin & 800 & 9 & 23 & NR & 9 & NR \\
\hline & & 59 & 21 & Usual care & 800 & 17 & 40 & NR & 17 & NR \\
\hline \multirow[t]{2}{*}{2002} & FLORIDA $^{39}$ & 61 & 19 & Fluvastatin & 265 & 2 & 7 & 2 & NR & NR \\
\hline & & 60 & 15 & Placebo & 275 & 1 & 11 & 1 & NR & NR \\
\hline 2002 & LIPS $^{41}$ & 60 & 15.8 & Fluvastatin & 844 & 2 & 36 & 2 & $N R$ & NR \\
\hline & & 60 & 16.6 & Placebo & 833 & $\mathrm{I}$ & 49 & I & $N R$ & NR \\
\hline 2002 & PROSPER - & 75.3 & 51.7 & Pravastatin & 2,891 & 135 & 298 & 22 & 116 & 77 \\
\hline & secondary ${ }^{23}$ & 75.4 & 51.7 & Placebo & 2,913 & $13 \mid$ & 306 & 14 & 119 & 102 \\
\hline 2003 & TREAT TO & 63 & 24.3 & Atorvastatin & 556 & 0 & 0 & 0 & NR & NR \\
\hline & TARGET $^{52}$ & 62.5 & 24.8 & Simvastatin & 537 & 0 & 0 & 0 & NR & NR \\
\hline 2004 & PROVE & 58.1 & 22.2 & Atorvastatin & 2,099 & 21 & 46 & NR & 21 & NR \\
\hline & IT-TIMI ${ }^{45}$ & 58.3 & 21.6 & Pravastatin & 2,063 & 21 & 66 & NR & 21 & NR \\
\hline 2004 & $\mathrm{PACT}^{24}$ & NR & 23.5 & Pravastatin & I,710 & NR & 24 & NR & $N R$ & NR \\
\hline & & NR & 24.3 & Placebo & 1,698 & $N R$ & 37 & $N R$ & $N R$ & NR \\
\hline 2004 & Bae et $\mathrm{al}^{28}$ & 60 & 37 & Atorvastatin & 105 & 1 & 0 & 0 & 1 & NR \\
\hline & & 60 & 27 & Usual care & 100 & 1 & 0 & 0 & 1 & NR \\
\hline 2004 & ALLIANCE ${ }^{30}$ & 61.1 & 17.8 & Atorvastatin & 1,217 & 35 & 121 & 35 & NR & NR \\
\hline & & 61.3 & 17.7 & Usual care & 1,225 & 39 & 127 & 39 & $N R$ & NR \\
\hline 2004 & $\mathrm{PCS}^{19}$ & 59.2 & 91 & Pravastatin & 54 & 3 & 5 & 0 & 3 & NR \\
\hline & & 59.9 & 92 & Diet & 66 & 4 & 3 & 0 & 4 & NR \\
\hline 2004 & REVERSAL ${ }^{51}$ & NA & NA & Atorvastatin & 327 & 1 & 1 & NR & 1 & NR \\
\hline & & NA & NA & Pravastatin & 327 & 1 & 1 & NR & I & NR \\
\hline 2005 & $\mathrm{PCABG}^{18}$ & 59.6 & 19.7 & Pravastatin & 152 & I & 6 & 0 & 1 & 0 \\
\hline & & 58.2 & 11.9 & Placebo & $|5|$ & 6 & 11 & $\mathrm{I}$ & 5 & 1 \\
\hline 2005 & IDEAL $^{53}$ & 61.6 & 19.2 & Atorvastatin & 4,439 & NR & 366 & NR & $N R$ & NR \\
\hline & & 61.8 & 19.1 & Simvastatin & 4,449 & NR & 374 & NR & NR & NR \\
\hline
\end{tabular}


Table I (Continued)

\begin{tabular}{|c|c|c|c|c|c|c|c|c|c|c|}
\hline Year & Trial name & $\begin{array}{l}\text { Mean } \\
\text { age, years }\end{array}$ & $\%$ woman & Treatment & $\begin{array}{l}\text { Number } \\
\text { randomized }\end{array}$ & $\begin{array}{l}\text { Major } \\
\text { cerebrovascular } \\
\text { events, } \mathbf{n}\end{array}$ & $\begin{array}{l}\text { All-cause } \\
\text { death, } n\end{array}$ & $\begin{array}{l}\text { Fatal } \\
\text { stroke, n }\end{array}$ & $\begin{array}{l}\text { Nonfatal } \\
\text { stroke, n }\end{array}$ & TIA, n \\
\hline \multirow[t]{2}{*}{2005} & Stone et $\mathrm{al}^{32}$ & NR & 14 & Atorvastatin & 96 & 1 & $\mathrm{I}$ & NR & $\mathrm{I}$ & NR \\
\hline & & NR & 12 & Placebo & 103 & 0 & 0 & NR & 0 & NR \\
\hline \multirow[t]{2}{*}{2005} & ATHEROMA $^{25}$ & NA & NA & Pravastatin & 186 & 5 & I & NR & 5 & NR \\
\hline & & NA & NA & Diet & 187 & 4 & 2 & NR & 4 & NR \\
\hline \multirow[t]{2}{*}{2006} & $\mathrm{SPARCL}^{26}$ & 63 & 39.7 & Atorvastatin & 2,365 & 165 & 216 & 24 & 247 & 153 \\
\hline & & 62.5 & 41 & Placebo & 2,366 & 311 & 211 & 41 & 280 & 208 \\
\hline \multirow[t]{2}{*}{2006} & ASPEN - & 60.5 & 38 & Atorvastatin & 252 & 7 & 26 & NR & NR & NR \\
\hline & secondary $^{29}$ & 60.4 & 37 & Placebo & 253 & 9 & 27 & NR & NR & NR \\
\hline \multirow[t]{2}{*}{2007} & $\mathrm{SAGE}^{46}$ & 72.4 & 31.2 & Atorvastatin & 446 & NR & 6 & NR & NR & NR \\
\hline & & 72.6 & 29.9 & Pravastatin & 445 & NR & 18 & NR & NR & NR \\
\hline \multirow[t]{2}{*}{2007} & CORONA $^{42}$ & 73 & 24 & Rosuvastatin & 2,514 & 103 & 728 & 14 & 89 & NR \\
\hline & & 73 & 24 & Placebo & 2,497 & 115 & 759 & 11 & 104 & NR \\
\hline \multirow[t]{2}{*}{2008} & GISSI-HF ${ }^{43}$ & 68 & 23.8 & Rosuvastatin & 2,285 & 82 & 657 & 38 & 44 & NR \\
\hline & & 68 & 21.4 & Placebo & 2,289 & 66 & 644 & 29 & 37 & NR \\
\hline \multirow[t]{2}{*}{2008} & OACIS-LIPID ${ }^{22}$ & 63.6 & 26.7 & Pravastatin & 176 & 0 & 3 & NR & 0 & NR \\
\hline & & 62.9 & 19.8 & Usual care & 177 & 2 & 2 & NR & 2 & NR \\
\hline \multirow[t]{2}{*}{2009} & SPACE & 62.1 & 20.7 & Rosuvastatin & 633 & 2 & 11 & NR & 2 & 1 \\
\hline & ROCKET $^{47}$ & 62.5 & 20.5 & Simvastatin & 630 & 0 & 16 & NR & 0 & 2 \\
\hline \multirow[t]{2}{*}{2010} & $\mathrm{FACS}^{40}$ & 60.9 & 29.5 & Fluvastatin & 78 & 1 & 1 & NR & 1 & NR \\
\hline & & 63.2 & 34.6 & Placebo & 78 & 3 & 4 & NR & 3 & NR \\
\hline \multirow[t]{2}{*}{2010} & CENTAURUS ${ }^{49}$ & NA & NA & Rosuvastatin & 406 & 3 & 2 & 0 & 3 & NR \\
\hline & & NA & NA & Atorvastatin & 423 & 0 & 4 & NR & 0 & NR \\
\hline \multirow[t]{2}{*}{2011} & SATURN $^{50}$ & 57.4 & 27.1 & Rosuvastatin & 520 & 3 & NR & NR & 3 & NR \\
\hline & & 57.9 & 25.6 & Atorvastatin & 519 & 2 & NR & NR & 2 & NR \\
\hline \multirow[t]{3}{*}{2012} & LUNAR $^{54}$ & 52.9 & 11.2 & Atorvastatin & 278 & NR & I & NR & NR & NR \\
\hline & & 53 & 15.3 & 20 rosuvastatin & 277 & NR & 0 & NR & NR & NR \\
\hline & & 52.8 & 15.9 & 40 rosuvastatin & 270 & NR & 2 & NR & NR & NR \\
\hline \multirow[t]{2}{*}{2013} & PEARL $^{44}$ & 62.9 & 19.1 & Pitavastatin & 289 & 8 & 27 & NR & 8 & NR \\
\hline & & 62.2 & 17.8 & Control & 288 & 9 & 37 & NR & 9 & NR \\
\hline \multirow[t]{2}{*}{2015} & ALPS-AMI ${ }^{48}$ & 65.7 & 19 & Pravastatin & $26 I$ & 10 & 14 & 5 & 5 & NR \\
\hline & & 66.3 & 19.6 & Atorvastatin & 264 & 5 & 9 & 4 & I & NR \\
\hline
\end{tabular}

Abbreviations: TIA, transient ischemic attack; NR, not reported; NA, not applicable.

\section{Comparative benefits of statins on major CVEs: findings of the multiple-treatment meta-analyses}

In 32 studies comparing statins treatment and control treatment, major CVEs were reported in 27 studies $^{13-15}$ $18-23,25-32,34-36,38-44$ in which there were 66,007 patients and a total of 2,057 major CVEs. In the secondary prevention of cardiovascular diseases, results showed that pravastatin and atorvastatin could reduce the incidence of major CVEs by $13 \%$ and $41 \%$, respectively, compared with the control group, but there was no significant difference between other statins and control (Table 2). In 10 headhead studies, ${ }^{45-54}$ the influence of statins on the major CVEs was reported in seven studies, ${ }^{45,47-52}$ in which there were 9,565 patients and a total of 69 major CVEs. Paired comparison in network meta-analysis showed a significant difference only between atorvastatin and rosuvastatin (RR 1.7,1.10-2.50).

\section{Comparative benefits of statins on all-cause mortality: findings of the multiple-treatment meta-analyses}

The all-cause death was investigated in 40 studies, ${ }^{13-20,22-49,51-54}$ in which there were 76,483 patients and 7,328 deaths. Of included studies, statin treatment was compared with control treatment in 31 studies, in which there were 6,391 deaths occurring in 57,354 patients; comparison between two statin treatments was found in 10 studies, ${ }^{42,45-49,51-54}$ in which there were 937 deaths occurring in 19,133 patients. Direct meta-analysis showed that the mortality of any cause in statin-treated patients was reduced by $12 \%$ compared to the control group (RR 0.88, 0.81-0.96), and a significant 


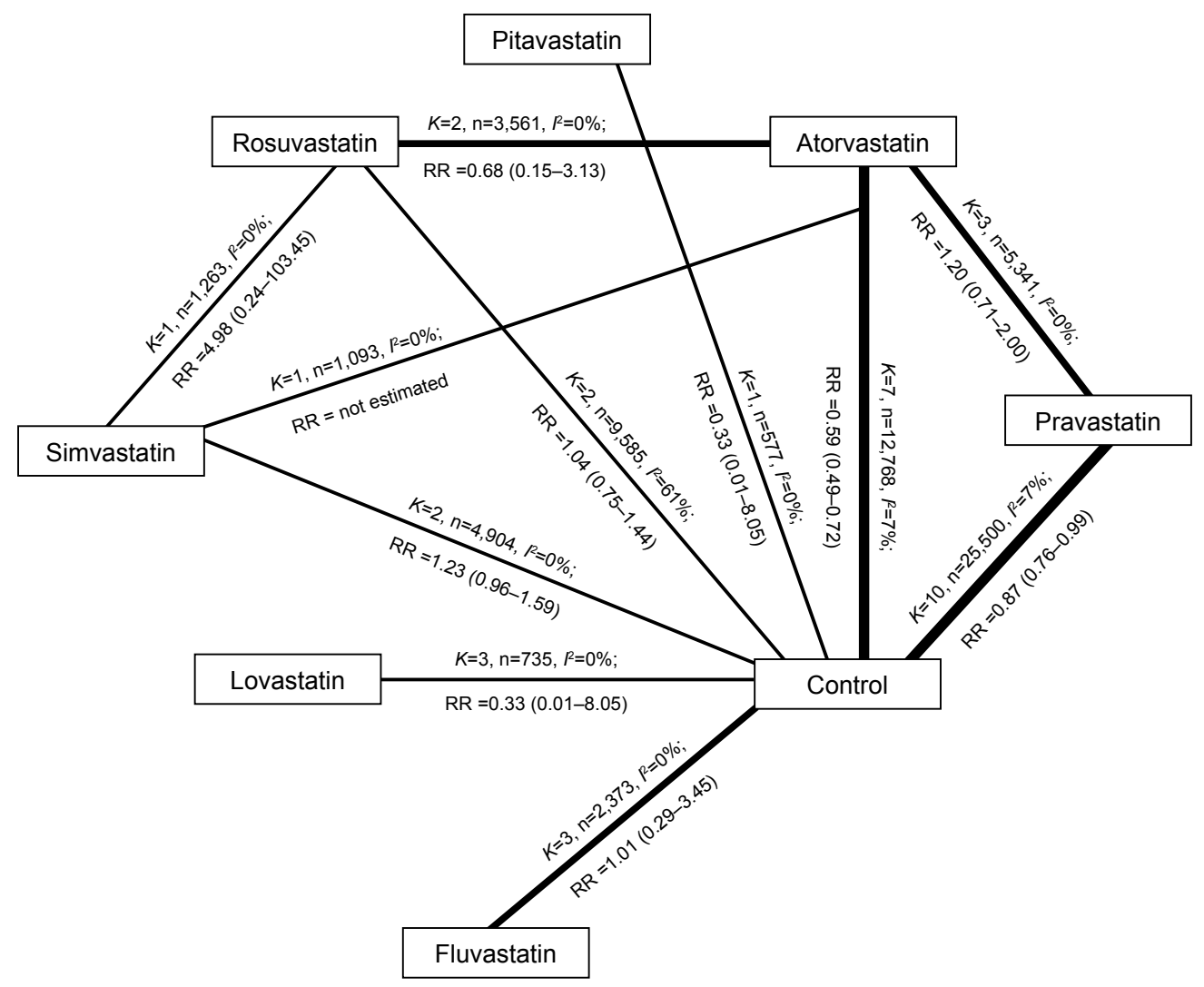

Figure 2 Meta-analysis of seven statins in the prevention of major CVEs.

Notes: Rosuvastatin vs atorvastatin: $K=2, \mathrm{n}=3,56 \mathrm{I}, P^{2}=0 \%$; $R R=0.68$ ( $\left.0.15-3.13\right)$; atorvastatin vs simvastatin: $K=I, \mathrm{n}=1,093, P=0 \%$; $R R=$ not estimated; rosuvastatin vs control: $K=2, \mathrm{n}=9,585, I^{2}=61 \%$; $\mathrm{RR}=1.04(0.75-1.44)$; atorvastatin vs pravastatin: $K=3, \mathrm{n}=5,34 \mathrm{I}, I^{2}=0 \%$; $\mathrm{RR}=1.20(0.7 \mathrm{I}-2.00)$ and atorvastatin vs control: $K=7, \mathrm{n}=12,768, I^{2}=7 \%$; $R R=0.59$ (0.49-0.72).

Abbreviations: CVE, cerebrovascular event; RR, risk ratio.

difference was only noted between the pravastatin group and the control group (RR 0.84, 0.76-0.94). Comparison between two treatments showed significant difference between pravastatin and atorvastatin (RR 1.60, 1.17-2.19),

Table 2 Network meta-analysis of prevention of major CVEs: direction comparisons between statin treatment and control treatment as well as different statin treatments

\begin{tabular}{ll}
\hline Treatment comparison & RR $(95 \% \mathbf{C I})$ \\
\hline Stain treatment vs control treatment & \\
Pravastatin vs control & $0.87(0.76-0.99)$ \\
Atorvastatin vs control & $0.59(0.49-0.72)$ \\
Fluvastatin vs control & $\mathrm{I} .0 \mathrm{I}(0.29-3.45)$ \\
Simvastatin vs control & $\mathrm{I} .23(0.96-\mathrm{I} .59)$ \\
Lovastatin vs control & $0.33(0.0 \mathrm{I}-8.05)$ \\
Rosuvastatin vs control & $\mathrm{I} .04(0.75-\mathrm{I} .44)$ \\
Pitavastatin vs control & $0.89(0.35-2.26)$ \\
All statins vs control & $0.88(0.7 \mathrm{I}-\mathrm{I} .10)$ \\
Two different statin treatments & \\
Pravastatin vs atorvastatin & $\mathrm{I} .20(0.7 \mathrm{I}-2.00)$ \\
Atorvastatin vs rosuvastatin & $0.68(0.15-3.13)$ \\
Rosuvastatin vs simvastatin & $4.98(0.24-103.45)$ \\
\hline
\end{tabular}

Abbreviations: CVEs, cerebrovascular events; RR, risk ratio. but network meta-analysis showed a marked difference only between fluvastatin and lovastatin (RR 3.60, 1.10-14.00; Table 3).

\section{Comparative benefits of statins on nonfatal and fatal strokes: findings of the multiple-treatment meta-analyses}

Of the studies on pitavastatin, fatal stroke had never been reported. In 19 studies with 41,144 patients, ${ }^{14,15,17-20 \text {, }}$ $23,26,28,30,31,34,36,39,41-43,48,52$ the fatal stroke was reported in 323 patients. In 26 studies, ${ }^{14,18-23,25-28,31,32,35,36,38,40,42-45,47-51}$ nonfatal stroke was reported as an outcome, and it was found in 1,529 patients among 49,710 patients included in these studies. Direct meta-analysis showed no significant difference between statin treatment and control treatment as well as between two statin treatments. Table 4 summarizes the results of network meta-analysis of fatal stroke and nonfatal stroke. Our results showed that significant difference was observed in the nonfatal stroke only between atorvastatin and simvastatin (RR 1.9, 1.1-3.7). 

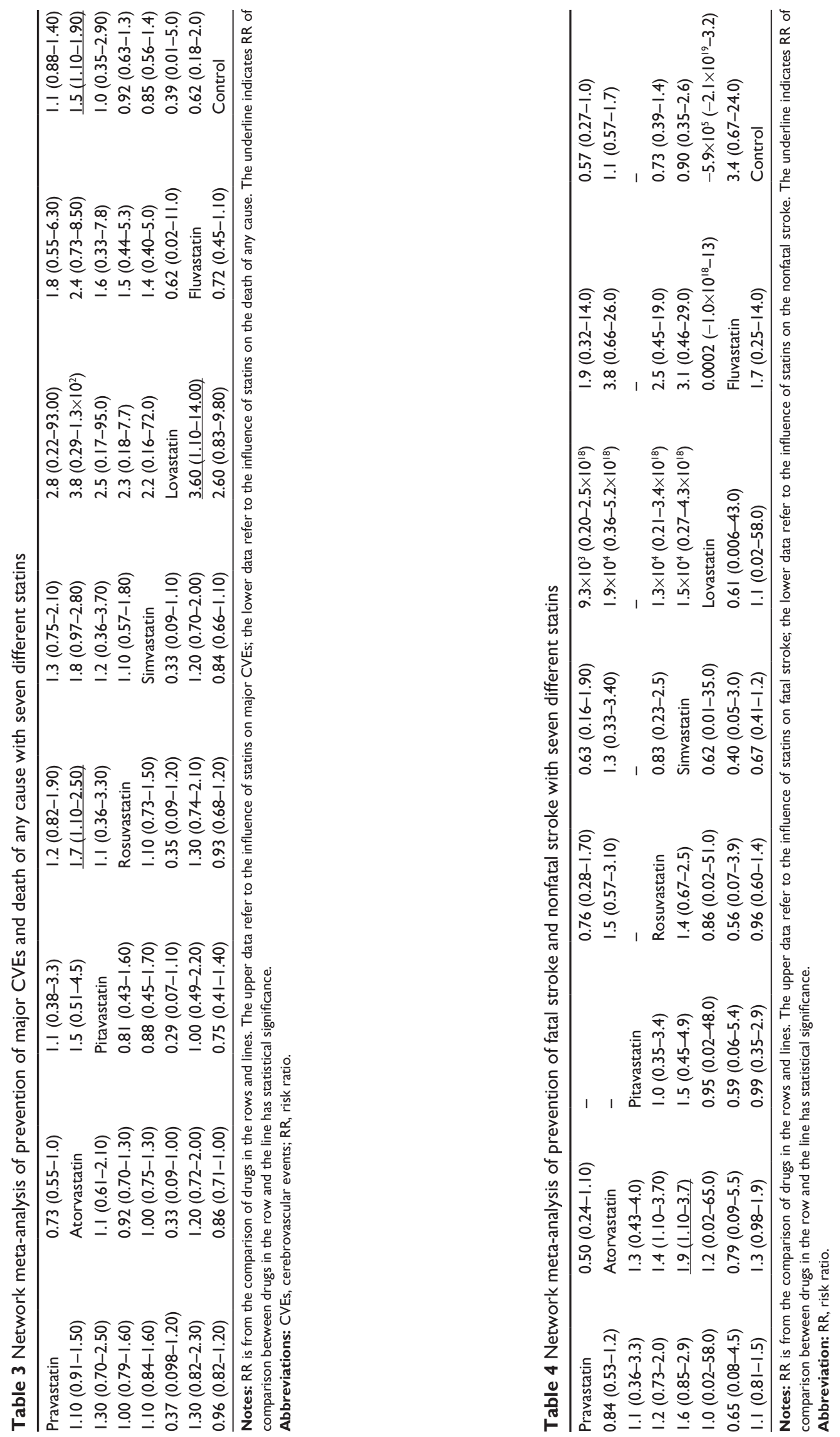


\section{Discussion}

This meta-analysis was based on 42 studies in which a total of 82,601 subjects randomly received treatment with seven different statins. Statistical and clinical differences were found in several statins. Our results showed that, in the secondary prevention of cardiovascular diseases, the mortality of any cause was reduced by $12 \%$ after statin treatment compared to the control treatment; the incidence of major CVEs was reduced by $13 \%$ and $41 \%$ after treatment with pravastatin and atorvastatin, respectively, compared with the control treatment. Indirect comparison with network meta-analysis showed that rosuvastatin was better than atorvastatin in the prevention of major CVEs and fluvastatin was better than lovastatin in the prevention of nonfatal stroke when statins were used in the secondary prevention of cardiovascular diseases.

Statins have pleiotropic effects, including the lipidlowering, vasodilation, anti-thrombotic, anti-inflammatory and anti-oxidative effects. ${ }^{55-62}$ Animal experiments and clinical studies have shown that statins may exert neuroprotective effects after acute cerebral infarction. ${ }^{63-65}$ Our results further confirmed and expanded previous results from meta-analysis. Clinical guideline recommends the use of statins in the secondary prevention of noncardiac stroke. ${ }^{66}$ To reduce LDL-C has been one of important strategies in the clinical prevention of cardiovascular events, and undoubtedly statins, are the most effective drugs used to reduce LDL-C. Statins may competitively inhibit hydroxymethylglutaryl coenzyme A (HMG-CoA) reductase, which is a rate-limiting enzyme in the endogenous cholesterol synthesis, and then block the metabolism of intracellular hydroxymaleic acid and reduce the endogenous production of cholesterol, exerting lipid-lowering effect. Although different statins have the identical mechanism in their lipid-lowering effect, the difference in the chemical structure among these statins makes their physical characteristics and internal pharmacokinetics different. SPARCL was the only one study that investigated the influence of statins used for secondary prevention on the TIA and stroke, ${ }^{26}$ but we could not expand their results to the use of other statins. In this study, meta-analysis was conducted in the population with cardiovascular diseases who were medicated with statins for the secondary prevention, and results showed difference among several statins. Probably, the actual difference among other statins might not be identified by this meta-analysis.

In this study, the majority of clinical trials included did not fully report the information about the randomization and allocation concealment, which may compromise the overall validity. Of note, the studies on different statins had similarities on the study design and implementation, and the lack of information about the quality assessment might be ascribed to the manuscript drafting but not to the actual defect in study design as shown in other systemic reviews. ${ }^{67}$ In our study, new network meta-analysis was used, and placebo-controlled and active comparator trials were merged to investigate the head-head studies of statins. Our study was different from previous network analysis: 1) not only placebo-controlled trials but also active comparator trials were included for analysis; 2) our study was an update of previous studies, and studies investigating seven commercially available statins (cerivastatin is not commercially available due to adverse effects) were included for analysis, which was not found in previous meta-analysis of stroke and 3 ) in this study, the major CVEs served as the main outcomes, but cardiovascular events were used as main outcomes in previous meta-analyses.

There were limitations in this study. First, this was a meta-analysis based on previous studies, and the number of studies included was limited. Only a few prospective, headhead clinical trials with clinical outcome were identified in the available studies. Second, the meta-analysis based on the data from published studies was limited by the quality of these studies. For example, the included studies that reported major CVEs might not report the fatal stroke. Third, there was a difference in the results of direct and indirect analyses, but direct comparison would make the results be more likely to be true. This difference might be related to the small sample size and the conservative nature of the Bayesian hierarchical random-effects model.

\section{Conclusion}

Different statins have distinct pharmacological characteristics and there are differences of statistical and clinical outcome among several statins.

\section{Disclosure}

The authors report no conflicts of interest in this work.

\section{References}

1. Kernan WN, Ovbiagele B, Black HR, et al. Guidelines for the prevention of stroke in patients with stroke and transient ischemic attack: a guideline for healthcare professionals from the American Heart Association/ American Stroke Association. Stroke. 2014;45(7):2160-2236.

2. Finkel JB, Duffy D. 2013 ACC/AHA cholesterol treatment guideline: paradigm shifts in managing atherosclerotic cardiovascular disease risk. Trends Cardiovasc Med. 2015;25(4):340-347.

3. Amarenco P, Labreuche J. Lipid management in the prevention of stroke: review and updated meta-analysis of statins for stroke prevention. Lancet Neurol. 2009;8(5):453-463. 
4. European Stroke Organisation (ESO) Executive Committee; ESO Writing Committee. Guidelines for management of ischaemic stroke and transient ischaemic attack 2008. Cerebrovasc Dis. 2008;25(5):457-507.

5. Chinese Society of Neurology, Neurology Cerebrovascular Group. 2014 Guideline of the secondary prevention of ischemic stroke and transient ischemic attack in China. Chin J Neurol. 2015;48(4):258-273.

6. Cannon CP, Steinberg BA, Murphy SA, Mega JL, Braunwald E. Metaanalysis of cardiovascular outcomes trials comparing intensive versus moderate statin therapy. J Am Coll Cardiol. 2006;48(3):438-445.

7. Zhou Z, Rahme E, Pilote L. Are statins created equal? Evidence from randomized trials of pravastatin, simvastatin, and atorvastatin for cardiovascular disease prevention. Am Heart J. 2006;151(2):273-281.

8. Naci H, Brugts JJ, Fleurence R, Ades AE. Comparative effects of statins on major cerebrovascular events: a multiple-treatments meta-analysis of placebo-controlled and active-comparator trials. QJM. 2013;106(4): 299-306.

9. Alberton M, Wu P, Druyts E, Briel M, Mills EJ. Adverse events associated with individual statin treatments for cardiovascular disease: an indirect comparison meta-analysis. QJM. 2012;105(2):145-157.

10. Mills EJ, Rachlis B, Wu P, Devereaux PJ, Arora P, Perri D. Primary prevention of cardiovascular mortality and events with statin treatments: a network meta-analysis involving more than 65,000 patients. $J$ Am Coll Cardiol. 2008;52(22):1769-1781.

11. Mills EJ, Wu P, Chong G, et al. Efficacy and safety of statin treatment for cardiovascular disease: a network meta-analysis of 170,255 patients from 76 randomized trials. QJM. 2011;104(2):109-124.

12. Ribeiro RA, Ziegelmann PK, Duncan BB, et al. Impact of statin dose on major cardiovascular events: a mixed treatment comparison metaanalysis involving more than 175,000 patients. Int J Cardiol. 2013; 166(2):431-439.

13. The Long-Term Intervention with Pravastatin in Ischaemic Disease (LIPID) Study Group. Prevention of cardiovascular events and death with pravastatin in patients with coronary heart disease and a broad range of initial cholesterol levels. N Engl J Med. 1998;339(19):1349-1357.

14. Results of the low-dose $(20 \mathrm{mg})$ pravastatin GISSI Prevenzione trial in 4271 patients with recent myocardial infarction: do stopped trials contribute to overall knowledge? GISSI Prevenzione Investigators (Gruppo Italiano per lo Studio della Sopravvivenza nell'Infarto Miocardico). Ital Heart J. 2000;1(12):810-820.

15. Bertrand ME, McFadden EP, Fruchart JC, et al. Effect of pravastatin on angiographic restenosis after coronary balloon angioplasty. The PREDICT Trial Investigators. Prevention of restenosis by elisor after transluminal coronary angioplasty. J Am Coll Cardiol. 1997;30(4):863-869.

16. Crouse JR 3rd, Byington RP, Bond MG, et al. Pravastatin, lipids, and atherosclerosis in the carotid arteries (PLAC-II). Am J Cardiol. 1995; 75(7):455-459.

17. Jukema JW, Bruschke AV, van Boven AJ, et al. Effects of lipid lowering by pravastatin on progression and regression of coronary artery disease in symptomatic men with normal to moderately elevated serum cholesterol levels. The Regression Growth Evaluation Statin Study (REGRESS). Circulation. 1995;91(10):2528-2540.

18. Makuuchi H, Furuse A, Endo M, et al. Effect of pravastatin on progression of coronary atherosclerosis in patients after coronary artery bypass surgery. Circ J. 2005;69(6):636-643.

19. Nakagawa T, Kobayashi T, Awata N, et al. Randomized, controlled trial of secondary prevention of coronary sclerosis in normocholesterolemic patients using pravastatin: final 5-year angiographic follow-up of the Prevention of Coronary Sclerosis (PCS) study. Int J Cardiol. 2004;97(1):107-114.

20. Pitt B, Mancini GB, Ellis SG, Rosman HS, Park JS, McGovern ME. Pravastatin limitation of atherosclerosis in the coronary arteries (PLAC I): reduction in atherosclerosis progression and clinical events. PLAC I investigation. J Am Coll Cardiol. 1995;26(5):1133-1139.

21. Sacks FM, Pfeffer MA, Moye LA, et al. The effect of pravastatin on coronary events after myocardial infarction in patients with average cholesterol levels. Cholesterol and Recurrent Events Trial investigators. N Engl J Med. 1996;335(14):1001-1009.
22. Sato H, Kinjo K, Ito H, et al. Effect of early use of low-dose pravastatin on major adverse cardiac events in patients with acute myocardial infarction: the OACIS-LIPID Study. Circ J. 2008;72(1):17-22.

23. Shepherd J, Blauw GJ, Murphy MB, et al. Pravastatin in elderly individuals at risk of vascular disease (PROSPER): a randomised controlled trial. Lancet. 2002;360(9346):1623-1630.

24. Thompson PL, Meredith I, Amerena J, Campbell TJ, Sloman JG, Harris PJ. Effect of pravastatin compared with placebo initiated within 24 hours of onset of acute myocardial infarction or unstable angina: the Pravastatin in Acute Coronary Treatment (PACT) trial. Am Heart J. 2004;148(1):e2.

25. Yokoi H, Nobuyoshi M, Mitsudo K, Kawaguchi A, Yamamoto A; ATHEROMA Study Investigators. Three-year follow-up results of angiographic intervention trial using an $\mathrm{HMG}-\mathrm{CoA}$ reductase inhibitor to evaluate retardation of obstructive multiple atheroma (ATHEROMA) study. Circ J. 2005;69(8):875-883.

26. Amarenco P, Bogousslavsky J, Callahan A 3rd, et al. High-dose atorvastatin after stroke or transient ischemic attack. $N$ Engl J Med. 2006; 355(6):549-559.

27. Athyros VG, Kakafika AI, Papageorgiou AA, et al. Effects of statin treatment in men and women with stable coronary heart disease: a subgroup analysis of the GREACE Study. Curr Med Res Opin. 2008; 24(6):1593-1599.

28. Bae JH, Bassenge E, Kim KY, Synn YC, Park KR, Schwemmer M. Effects of low-dose atorvastatin on vascular responses in patients undergoing percutaneous coronary intervention with stenting. $J$ Cardiovasc Pharmacol Ther. 2004;9(3):185-192.

29. Knopp RH, d'Emden M, Smilde JG, Pocock SJ. Efficacy and safety of atorvastatin in the prevention of cardiovascular end points in subjects with type 2 diabetes: the Atorvastatin Study for Prevention of Coronary Heart Disease Endpoints in non-insulin-dependent diabetes mellitus (ASPEN). Diabetes Care. 2006;29(7):1478-1485.

30. Koren MJ, Hunninghake DB. Clinical outcomes in managed-care patients with coronary heart disease treated aggressively in lipidlowering disease management clinics: the alliance study. $J$ Am Coll Cardiol. 2004;44(9):1772-1779.

31. Schwartz GG, Olsson AG, Ezekowitz MD, et al. Effects of atorvastatin on early recurrent ischemic events in acute coronary syndromes: the MIRACL study: a randomized controlled trial. JAMA. 2001;285(13):1711-1718.

32. Stone PH, Lloyd-Jones DM, Kinlay S, et al. Effect of intensive lipid lowering, with or without antioxidant vitamins, compared with moderate lipid lowering on myocardial ischemia in patients with stable coronary artery disease: the vascular basis for the treatment of Myocardial Ischemia Study. Circulation. 2005;111(14):1747-1755.

33. Blankenhorn DH, Azen SP, Kramsch DM, et al. Coronary angiographic changes with lovastatin therapy. The Monitored Atherosclerosis Regression Study (MARS). Ann Intern Med. 1993;119(10): 969-976.

34. Waters D, Higginson L, Gladstone P, et al. Effects of monotherapy with an HMG-CoA reductase inhibitor on the progression of coronary atherosclerosis as assessed by serial quantitative arteriography. The Canadian Coronary Atherosclerosis Intervention Trial. Circulation. 1994;89(3):959-968.

35. Weintraub WS, Boccuzzi SJ, Klein JL, et al. Lack of effect of lovastatin on restenosis after coronary angioplasty. Lovastatin Restenosis Trial Study Group. N Engl J Med. 1994;331(20):1331-1337.

36. Randomised trial of cholesterol lowering in 4444 patients with coronary heart disease: the Scandinavian Simvastatin Survival Study (4S). Lancet. 1994;344(8934):1383-1389.

37. Effect of simvastatin on coronary atheroma: the Multicentre AntiAtheroma Study (MAAS). Lancet. 1994;344(8923):633-638.

38. Teo KK, Burton JR, Buller CE, et al. Long-term effects of cholesterol lowering and angiotensin-converting enzyme inhibition on coronary atherosclerosis: the Simvastatin/Enalapril Coronary Atherosclerosis Trial (SCAT). Circulation. 2000;102(15):1748-1754.

39. Liem AH, van Boven AJ, Veeger NJ, et al. Effect of fluvastatin on ischaemia following acute myocardial infarction: a randomized trial Eur Heart J. 2002;23(24):1931-1937. 
40. Ostadal P, Alan D, Vejvoda J, et al. Fluvastatin in the first-line therapy of acute coronary syndrome: results of the multicenter, randomized, doubleblind, placebo-controlled trial (the FACS-trial). Trials. 2010;11:61.

41. Serruys PW, de Feyter P, Macaya C, et al. Fluvastatin for prevention of cardiac events following successful first percutaneous coronary intervention: a randomized controlled trial. JAMA. 2002;287(24): 3215-3222.

42. Kjekshus J, Apetrei E, Barrios V, et al. Rosuvastatin in older patients with systolic heart failure. N Engl J Med. 2007;357(22):2248-2261.

43. Tavazzi L, Maggioni AP, Marchioli R, et al. Effect of rosuvastatin in patients with chronic heart failure (the GISSI-HF trial): a randomised, doubleblind, placebo-controlled trial. Lancet. 2008;372(9645):1231-1239.

44. Takano H, Mizuma H, Kuwabara Y, et al. Effects of pitavastatin in Japanese patients with chronic heart failure: the Pitavastatin Heart Failure Study (PEARL Study). Circ J. 2013;77(4):917-925.

45. Cannon $\mathrm{CP}$, Braunwald $\mathrm{E}, \mathrm{McCabe} \mathrm{CH}$, et al. Intensive versus moderate lipid lowering with statins after acute coronary syndromes. $N$ Engl J Med. 2004;350(15):1495-1504.

46. Deedwania P, Stone PH, Bairey Merz CN, et al. Effects of intensive versus moderate lipid-lowering therapy on myocardial ischemia in older patients with coronary heart disease: results of the Study Assessing Goals in the Elderly (SAGE). Circulation. 2007;115(6):700-707.

47. Hall AS, Jackson BM, Farrin AJ, et al. A randomized, controlled trial of simvastatin versus rosuvastatin in patients with acute myocardial infarction: the Secondary Prevention of Acute Coronary Events Reduction of Cholesterol to Key European Targets Trial. Eur JCardiovasc Prev Rehabil. 2009;16(6):712-721.

48. Izawa A, Kashima Y, Miura T, et al. Assessment of lipophilic vs. hydrophilic statin therapy in acute myocardial infarction - ALPS-AMI study. Circ J. 2015;79(1):161-168.

49. Lablanche JM, Leone A, Merkely B, et al. Comparison of the efficacy of rosuvastatin versus atorvastatin in reducing apolipoprotein B/ apolipoprotein A-1 ratio in patients with acute coronary syndrome: results of the CENTAURUS study. Arch Cardiovasc Dis. 2010;103(3): 160-169.

50. Nicholls SJ, Ballantyne CM, Barter PJ, et al. Effect of two intensive statin regimens on progression of coronary disease. NEngl JMed. 2011; 365(22):2078-2087.

51. Nissen SE, Tuzcu EM, Schoenhagen P, et al. Effect of intensive compared with moderate lipid-lowering therapy on progression of coronary atherosclerosis: a randomized controlled trial. JAMA. 2004;291(9):1071-1080.

52. Olsson AG, Eriksson M, Johnson O, et al. A 52-week, multicenter, randomized, parallel-group, double-blind, double-dummy study to assess the efficacy of atorvastatin and simvastatin in reaching low-density lipoprotein cholesterol and triglyceride targets: the treat-to-target (3T) study. Clin Ther. 2003;25(1):119-138.

53. Pedersen TR, Faergeman O, Kastelein JJ, et al. High-dose atorvastatin vs usual-dose simvastatin for secondary prevention after myocardial infarction: the IDEAL study: a randomized controlled trial. JAMA. 2005;294(19):2437-2445.
54. Pitt B, Loscalzo J, Monyak J, Miller E, Raichlen J. Comparison of lipid-modifying efficacy of rosuvastatin versus atorvastatin in patients with acute coronary syndrome (from the LUNAR study). Am J Cardiol. 2012;109(9):1239-1246.

55. Amin-Hanjani S, Stagliano NE, Yamada M, Huang PL, Liao JK, Moskowitz MA. Mevastatin, an HMG-CoA reductase inhibitor, reduces stroke damage and upregulates endothelial nitric oxide synthase in mice. Stroke. 2001;32(4):980-986.

56. Asahi M, Huang Z, Thomas S, et al. Protective effects of statins involving both eNOS and tPA in focal cerebral ischemia. J Cereb Blood Flow Metab. 2005;25(6):722-729.

57. Chen J, Zhang ZG, Li Y, et al. Statins induce angiogenesis, neurogenesis, and synaptogenesis after stroke. Ann Neurol. 2003;53(6):743-751.

58. Di Napoli P, Taccardi AA, Oliver M, De Caterina R. Statins and stroke: evidence for cholesterol-independent effects. Eur Heart J. 2002; 23(24):1908-1921.

59. Endres M, Laufs U, Huang Z, et al. Stroke protection by 3-hydroxy3-methylglutaryl (HMG)-CoA reductase inhibitors mediated by endothelial nitric oxide synthase. Proc Natl Acad Sci US A. 1998;95(15): 8880-8885.

60. Kawashima S, Yamashita T, Miwa Y, et al. HMG-CoA reductase inhibitor has protective effects against stroke events in stroke-prone spontaneously hypertensive rats. Stroke. 2003;34(1):157-163.

61. Sironi L, Cimino M, Guerrini U, et al. Treatment with statins after induction of focal ischemia in rats reduces the extent of brain damage. Arterioscler Thromb Vasc Biol. 2003;23(2):322-327.

62. Vaughan CJ, Delanty N. Neuroprotective properties of statins in cerebral ischemia and stroke. Stroke. 1999;30(9):1969-1973.

63. Elkind MS, Flint AC, Sciacca RR, Sacco RL. Lipid-lowering agent use at ischemic stroke onset is associated with decreased mortality. Neurology. 2005;65(2):253-258.

64. Hassan Y, Al-Jabi SW, Aziz NA, Looi I, Zyoud SH. Statin use prior to ischemic stroke onset is associated with decreased in-hospital mortality. Fundam Clin Pharmacol. 2011;25(3):388-394.

65. Marti-Fabregas J, Gomis M, Arboix A, et al. Favorable outcome of ischemic stroke in patients pretreated with statins. Stroke. 2004;35(5): 1117-1121.

66. Sacco RL, Adams R, Albers G, et al. Guidelines for prevention of stroke in patients with ischemic stroke or transient ischemic attack: a statement for healthcare professionals from the American Heart Association/ American Stroke Association Council on Stroke: co-sponsored by the Council on Cardiovascular Radiology and Intervention: the American Academy of Neurology affirms the value of this guideline. Circulation. 2006;113(10):e409-e449.

67. Huwiler-Muntener K, Juni P, Junker C, Egger M. Quality of reporting of randomized trials as a measure of methodologic quality. JAMA. 2002;287(21):2801-2804.
Drug Design, Development and Therapy

\section{Publish your work in this journal}

Drug Design, Development and Therapy is an international, peerreviewed open-access journal that spans the spectrum of drug design and development through to clinical applications. Clinical outcomes, patient safety, and programs for the development and effective, safe, and sustained use of medicines are the features of the journal, which

\section{Dovepress}

has also been accepted for indexing on PubMed Central. The manuscript management system is completely online and includes a very quick and fair peer-review system, which is all easy to use. Visit http://www.dovepress.com/testimonials.php to read real quotes from published authors. 